\title{
Randomized study to compare nasojejunal with nasogastric nutrition in critically ill patients without prior evidence of altered gastric emptying
}

\author{
Gilberto Friedman ${ }^{1,2}$, Cecilia Lopes Flávia Couto², Maicon Becker³
}

Background and Aims: Studies comparing jejunal and gastric nutrition show inconsistent results regarding pneumonia. The aim of this study was to evaluate the incidence of pneumonia comparing gastric with jejunal nutrition. Secondarily, we evaluated $28^{\text {th }}$ day Intensive Care Unit (ICU) mortality rate and other complications related to enteral feeding. Subjects: Age >18 years; need for enteral nutrition without contraindication for placement of an enteral tube, duration of ICU stay > than 48 h. Methods: Patients were randomly assigned to receive enteral feed via a gastric or jejunal tube. Jejunal tubes were inserted at bedside and placement was confirmed radiographically. Results: A total of II 5 patients were enrolled, with $6 \mathrm{I}$ patients into the gastric tube group and 54 patients into the jejunal group tube. Baseline characteristics were similar. There was no difference in pneumonia or ICU mortality rates, ICU length of stay and ventilator days. Complications rates were similar. Conclusions: We conclude that the enteral nutrition through a jejunal tube does not reduce the rate of pneumonia in comparison to a gastric tube. In addition, we did not observe differences in rates of gastrointestinal complications or ICU mortality. The routine placement of a jejunal tube in critically ill-patients cannot be recommended.

Keywords: Critical illness, enteral nutrition, Intensive care units, nasojejunal, pneumonia, randomized controlled trial
Access this article online

Website: www.ijccm.org

DOI: 10.4103/0972-5229.151013

Quick Response Code:

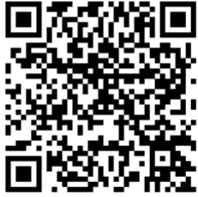

\section{Introduction}

Adequacy of nutritional support has significant importance in clinical outcomes of critically ill-patients. ${ }^{[1]}$ Nutritional therapy in critically ill-patients improves wound healing, reduces rates of certain complications and mortality seems to reduce. ${ }^{[2,3]}$ Enteral nutrition is recommended as the first option for most patients in light of the evidence of significant benefits while parenteral nutrition does not seem to add benefit to most critically ill-patients. ${ }^{[4-6]}$

From:

${ }^{1}$ Central Intensive Care Unit, Santa Casa Hospital, ${ }^{2}$ Federal University of Rio Grande do Sul, Porto Alegre, ${ }^{3}$ Pompeia Hospital, Caxias do Sul, Brazil

Correspondence:

Prof. Gilberto Friedman, Annes Dias St, 295, Porto Alegre, Brazil.

E-mail: gfriedman@hcpa.ufrgs.br
However, gastric intolerance is common, associated with the opioid or vasopressor use and shock, it reduces the energy delivery and can increase the incidence of nosocomial pneumonia. ${ }^{[7-9]}$ The slow gastric emptying may contribute to an increase in gastric residual volume predisposing to bacterial colonization and the occurrence of aspiration pneumonia in critically ill-patients. The nutrition by a postpyloric tube can overcome the difficulty of gastric emptying, and as the jejunum has a higher absorptive capacity and is less susceptible to decreased motility, it could be advantageous. ${ }^{[10-12]}$

However, studies and meta-analyzes comparing nasojejunal and nasogastric nutrition show inconsistent results regarding the delivery of nutrition or of pneumonia even when patients at risk for reduced gastric motility are included. ${ }^{[4,13]} \mathrm{A}$ meta-analysis 
published in 2013 evaluated 15 randomized trials until 2011 and concluded that the incidence of pneumonia is increased. ${ }^{[11]}$ Davies et al., in the largest randomized trial comparing the use of nasogastric and nasojejunal tube, did not observe any significant differences in outcome. ${ }^{[13]}$ Our hypothesis is that the use of a jejunal tube does not reduce the incidence of nosocomial pneumonia. The primary objective of this study is to evaluate the incidence of pneumonia throughout the stay in Intensive Care Unit (ICU) comparing gastric with jejunal nutrition. Secondarily, we evaluated the mortality rate in the ICU until the $28^{\text {th }}$ day and other complications potentially related to enteral feeding.

\section{Methods}

Our study was a pragmatic, open, randomized, controlled trial. All patients admitted to a University ICU for a period of 12 months were eligible for the study. Data collection was performed after approval by the Research Ethics Committee which waived the informed consent considering that there is no consensus on the use of jejunal or gastric tube and the choice is a personal preference of the attending physician.

The following variables were obtained at baseline: Age, sex, primary diagnosis, Glasgow coma scale and score Acute Physiology and Chronic Health Evaluation II (APACHE II). ${ }^{[14]}$

\section{Inclusion criteria}

Age $>18$ years, need for enteral nutrition without contraindication for placement of naso or oroenteral tube, initiation of enteral feeding within $48 \mathrm{~h}$ of admission, duration of ICU stay >than $48 \mathrm{~h}$.

\section{Exclusion criteria}

Patients with previous anatomic and/or surgical alteration of the upper gastrointestinal (GI) tract that could prevent the insertion of the enteral tube, such as anastomoses and esophagectomy and; severe coagulopathy, patients with medical indication for postpyloric nutrition, gastrostomy or jejunostomy, contraindication to enteral nutrition, pregnancy, life expectancy of $<48 \mathrm{~h}$. Additionally, patients who had difficulties during insertion of the tube and those admitted with enteral feeding (jejunal or gastric) that the attending physician contraindicated change of tube for the purposes of the study were excluded.

A third person not involved and blinded to the study conducted the patients' randomization (with the aid of opaque envelopes) to gastric or jejunal tubes groups. The positioning of the tube was confirmed radiologically.

The complications related to the placement of the tubes were recorded by the researchers. Accidental removal was defined when the tube was partially or totally withdrawn by the patient or during routine care.

These patients were followed daily while in use of a feeding tube and up to the $28^{\text {th }}$ day of admission or discharge from the ICU.

The individual energy needs and the formulation of enteral nutrition were determined by clinical staff (doctors and nutritionists). After patient's clinical stabilization, a 12 French tube was placed for nasogastric feeding and placement was confirmed by auscultating the stomach while insufflating air. Patients assigned to nasojejunal nutrition had a nasojejunal tube inserted and as soon as practicable, tube position was assessed using plain radiograph without contrast. If the tube was not positioned in the jejunum, time was allowed for further spontaneous passage using pro-kinetic drugs (in the discretion of a physician in charge), sometimes with tube repositioning prior to repeating radiograph. The diet was continuously administered by an infusion pump. The patients were maintained in a semi-recumbent position at (between $30^{\circ}$ and $45^{\circ}$ ) unless contraindicated.

Study outcomes were described as follows: Primary (pneumonia rate) and secondary (mortality rate within 28 days of ICU admission, ICU stay duration, duration of mechanical ventilation (MV), diarrhea, vomiting and constipation). The clinical suspicion of pneumonia required the presence of a new or progressive infiltrate on chest X-ray (no other alternative explanation), and at least two of the following criteria: (a) Temperature $>38^{\circ} \mathrm{C}$ or $<36^{\circ} \mathrm{C}$, (b) leukocytosis or leukopenia $\geq 12.000 \mathrm{~mm}^{3} \leq 4.000 \mathrm{~mm}^{3}$, (c) purulent secretion from the bronchial tree (tracheal aspirates specimens were considered positive in the presence of $>10^{5} \mathrm{CFU} / \mathrm{ml}$ ) or a simplified Clinical Pulmonary Infectious Score $\geq 6$ points. ${ }^{[15]}$

The comparison between groups was performed by Student's $t$-test or Mann-Whitney test for continuous variables and Chi-square or Fisher exact test for categorical variables. The variables are expressed as mean \pm standard deviation whenever the distribution was normal, or median (confidence interval 25-75\%). 


\section{Results}

Seven hundred and twenty-three patients were evaluated over 12 months. One hundred and fifteen patients were enrolled, with 61 patients in the gastric tube group and 54 patients into the jejunal group tube. All patients received a nasal tube. The characteristics of the two groups on admission to the study were similar [Table 1]. The mean age of the 115 patients was $62 \pm 15$ years, with a minimum of 18 years and a maximum of 91 years. The female gender was prevalent (51.3\%). The most prevalent diagnoses on ICU admission were respiratory $(33 \%)$, and neurological $(26 \%)$ causes. The mean APACHE II score was $22 \pm 6$ and the Glasgow coma score had a median of $7 \cdot \cdot^{[3-14]}$ No cases of acute pancreatitis were included in the study.

There were no significant differences between the two groups in the occurrence of pneumonia, ICU mortality or until day 28 [Table 2]. The rates for the other outcomes were also similar between groups.

\section{Discussion}

We conducted a randomized controlled clinical trial comparing early nutrition nasojejunal with a nasogastric tube in critically ill-patients. We found that early jejunal nutrition did not reduce the rate of pneumonia. Furthermore, there were no differences in rates of vomiting or GI complications; duration of MV or hospitalization; and mortality rate.

Our findings showed that jejunal nutrition did not reduce mortality, duration of MV or ICU stay. Our results are consistent with the results of previous studies and systematic reviews. ${ }^{[12,13,16-18]}$ However, guidelines and experts in nutrition recommend routine use of the jejunal tube when possible, because of potentially beneficial effects on two outcomes, reduced risk of pneumonia and improvement in the delivery of nutrition. We evaluated the risk of pneumonia and did not confirm the beneficial effect of jejunal tube on this outcome.

Several previous studies found no differences in rates of pneumonia when compared jejunal to gastric ${ }^{[12,13,16,18]}$ nutrition. Davies et al. studied 180 patients randomized to receive feeding via nasogastric or nasojejunal tube and found no difference in the risk of ventilator associated pneumonia. ${ }^{[13]}$ Our study did not study only mechanically ventilated patients yet $>80 \%$ of them underwent MV. Other studies suggest that the incidence of pneumonia can be reduced when nutrition is delivered via nasojejunal tube. ${ }^{[17,19]}$ A recent meta-analysis concluded that the combined studies using postpyloric

\begin{tabular}{lcc}
\hline \multicolumn{3}{l}{ Table I: Characteristics of the sample population } \\
\hline Variables & $\begin{array}{c}\text { Nasogastric } \\
\text { tube }(\boldsymbol{n}=6 \mathrm{I})\end{array}$ & $\begin{array}{c}\text { Nasojejunal } \\
\text { tube }(\boldsymbol{n}=54)\end{array}$ \\
\hline Age (years)-mean \pm SD & $60 \pm$ I4 & $63 \pm$ I7 \\
Gender-n (\%) & $26(43)$ & $30(56)$ \\
Male & $35(57)$ & $24(44)$ \\
Female & & $3(6)$ \\
Diagnosis-n (\%) & $10(17)$ & $17(32)$ \\
Cardiac & $21(35)$ & $16(30)$ \\
Respiratory & $14(23)$ & $9(17)$ \\
Neurologic & $10(17)$ & $2(4)$ \\
Sepsis & $0(0)$ & $5(9)$ \\
Trauma & $5(8)$ & $1(2)$ \\
Surgical & $0(0)$ & $22 \pm 7$ \\
Other & $22 \pm 6$ & $10(3-14)$ \\
APACHE II & $7(3-13)$ & \\
GCS (median, Cl 25-75) &
\end{tabular}

No significant differences in characteristics between the two groups were observed. SD: Standard deviation; APACHE II: Acute physiology and chronic health evaluation II; $\mathrm{Cl}$ : Confidence interval; GCS: Glasgow coma scale

\begin{tabular}{|c|c|c|c|}
\hline Variables & $\begin{array}{l}\text { Nasogastric } \\
\text { tube }(n=61)\end{array}$ & $\begin{array}{l}\text { Nasojejunal } \\
\text { tube }(n=54)\end{array}$ & $P$ \\
\hline MV-n (\%) & $5 \mathrm{I}(84)$ & $44(82)$ & 0.957 \\
\hline MV duration (days)-median ( $\mathrm{Cl} 25-75)$ & $7(3-13)$ & $4(2-I I)$ & 0.241 \\
\hline ICU stay (days)-median ( $\mathrm{Cl} 25-75)$ & $12(8-20)$ & $10(7-2 I)$ & 0.444 \\
\hline ICU mortality-n (\%) & $22(36)$ & $20(37)$ & 1.000 \\
\hline Pneumonia-n (\%) & $12(20)$ & $13(24)$ & 0.730 \\
\hline Diarrhea-n (\%) & II (I8) & $15(28)$ & 0.306 \\
\hline Vomiting-n (\%) & $18(30)$ & $14(26)$ & 0.826 \\
\hline Constipation-n (\%) & $14(23)$ & $9(17)$ & 0.544 \\
\hline Total cost (US\$) & 467 & 1163 & - \\
\hline
\end{tabular}

feeding as the preferred route shows a decrease in the incidence of pneumonia. ${ }^{[11]}$ However, the results of the studies included in this meta-analysis do not make clear whether the rate of aspiration pneumonia, which would be more related to the place of delivery of nutrition, is actually increased and therefore there is no consensus that the postpyloric position is effective in reducing the incidence of pneumonia. In addition, there is a significant discrepancy in the selection of studies. Furthermore, this meta-analysis did not include the study of Davies et al. ${ }^{[13]}$ The differences may be explained in part by the different ventilator-associated pneumonia diagnosis criteria between studies and also by the insufficient number of patients to reach statistical significance.

Gastric intolerance manifested as an increased gastric residual and risk of vomiting would be the main explanation for an increased risk of aspiration and therefore pneumonia. The occurrence of vomiting was common in both groups, reflecting the decreased gastric motility, but the delivery of nutrition on jejunal position has not decreased vomiting or other GI complications. This result is in agreement with other studies and 
meta-analysis. ${ }^{[11,13,18]}$ The volume of gastric residual in our study was not assessed, which can be considered an important limitation. However, as noted earlier, there was no difference for vomiting and macroaspiration was not observed for either group.

Some guidelines and researchers suggest that tube feeding in postpyloric position in critical patients would be helpful in specific situations, particularly in patients with pancreatitis and gastric stasis as these patients have higher gastric intolerance. ${ }^{[1,20,21]}$ Our study did not exclude patients who might develop gastric stasis and still we did not observe differences between the two groups regarding GI complications.

The subject follows controversial, and the studies conducted so far have not provided a more definitive answer. Perhaps, therefore, the guidelines of the American Society of Parenteral and Enteral Nutrition, the Canadian Critical Care Clinical Practice Guidelines Committee suggest that there is no difference between the two types of tube positioning, but recommend the use of postpyloric tube position only in certain patients as in the case of occurrence of severe pancreatitis or elevated gastric residual volume. ${ }^{[22,23]}$ While the European Society of Parenteral and Enteral Nutrition assumes no difference in the position of the tube. ${ }^{[21]}$ The routine use of jejunal tube results in higher cost and requires more experience and training for insertion and confirmation by radiological examination or endoscopic positioning.

The strength of our study lies in the number of patients, comparable to a few studies ${ }^{[13,16,17,19]}$ and with similar results. However, our study has several limitations: Physicians were not blinded to assess the outcomes; nurses with different expertise performed the insertion of tubes. Some specific nutrition data were not collected, such as caloric balance administration or gastric residual volume. It was also not quantified the number of episodes of diarrhea and vomiting, the report was restricted or not to the occurrence of these outcomes. Furthermore, we did not evaluate the use of drugs that reduce or accelerate GI motility. We should be careful in extrapolating the study results to all our ICU patients as only $16 \%$ of patients were included during the study period, and more medical patients were studied.

\section{Conclusions}

We conclude that there is no difference in the rate of pneumonia when using the gastric or jejunal tube position. Additionally, we did not observe differences in rates of GI complications, ICU mortality. The routine placement of a jejunal tube in critically ill patients cannot be recommended.

\section{References}

1. Heyland DK, Dhaliwal R, Drover JW, Gramlich L, Dodek P, Canadian Critical Care Clinical Practice Guidelines Committee. Canadian clinical practice guidelines for nutrition support in mechanically ventilated, critically ill adult patients. JPEN J Parenter Enteral Nutr 2003;27:355-73.

2. Teixeira AC, Caruso L, Soriano FG. Nutrition support in an intensive care unit: Delivery versus requirements. Rev Bras Ter Intensiva 2006;18:331-7

3. Desai SV, McClave SA, Rice TW. Nutrition in the ICU: An evidence-based approach. Chest 2014;145:1148-57.

4. Zaloga GP. Parenteral nutrition in adult inpatients with functioning gastrointestinal tracts: Assessment of outcomes. Lancet 2006;367:1101-11.

5. Al-Omran M, Albalawi ZH, Tashkandi MF, Al-Ansary LA. Enteral versus parenteral nutrition for acute pancreatitis. Cochrane Database Syst Rev 2010; CD002837.

6. Doig GS, Simpson F, Sweetman EA, Finfer SR, Cooper DJ, Heighes PT, et al. Early parenteral nutrition in critically ill patients with short-term relative contraindications to early enteral nutrition: A randomized controlled trial. JAMA 2013;309:2130-8.

7. Marik PE, Zaloga GP. Early enteral nutrition in acutely ill patients: A systematic review. Crit Care Med 2001;29:2264-70.

8. Heyland DK, Tougas G, King D, Cook DJ. Impaired gastric emptying in mechanically ventilated, critically ill patients. Intensive Care Med 1996;22:1339-44.

9. Chapman MJ, Nguyen NQ, Deane AM. Gastrointestinal dysmotility: Clinical consequences and management of the critically ill patient. Gastroenterol Clin North Am 2011;40:725-39.

10. Heyland DK, Drover JW, MacDonald S, Novak F, Lam M. Effect of postpyloric feeding on gastroesophageal regurgitation and pulmonary microaspiration: Results of a randomized controlled trial. Crit Care Med 2001;29:1495-501.

11. Jiyong J, Tiancha H, Huiqin W, Jingfen J. Effect of gastric versus post-pyloric feeding on the incidence of pneumonia in critically ill patients: Observations from traditional and Bayesian random-effects meta-analysis. Clin Nutr 2013;32:8-15.

12. Montejo JC, Grau T, Acosta J, Ruiz-Santana S, Planas M, García-De-Lorenzo A, et al. Multicenter, prospective, randomized, single-blind study comparing the efficacy and gastrointestinal complications of early jejunal feeding with early gastric feeding in critically ill patients. Crit Care Med 2002;30:796-800.

13. Davies AR, Morrison SS, Bailey MJ, Bellomo R, Cooper DJ, Doig GS, et al. A multicenter, randomized controlled trial comparing early nasojejunal with nasogastric nutrition in critical illness. Crit Care Med 2012;40:2342-8.

14. Knaus WA, Draper EA, Wagner DP, Zimmerman JE. APACHE II: A severity of disease classification system. Crit Care Med 1985;13:818-29.

15. Esperatti M, Ferrer M, Theessen A, Liapikou A, Valencia M, Saucedo LM, et al. Nosocomial pneumonia in the intensive care unit acquired by mechanically ventilated versus nonventilated patients. Am J Respir Crit Care Med 2010;182:1533-9.

16. White H, Sosnowski K, Tran K, Reeves A, Jones M. A randomised controlled comparison of early post-pyloric versus early gastric feeding to meet nutritional targets in ventilated intensive care patients. Crit Care 2009;13:R187.

17. Acosta-Escribano J, Fernández-Vivas M, Grau Carmona T, Caturla-Such J, Garcia-Martinez M, Menendez-Mainer A, et al. Gastric versus transpyloric feeding in severe traumatic brain injury: A prospective, randomized trial. Intensive Care Med 2010;36:1532-9.

18. Ho KM, Dobb G.J, Webb SA. A comparison of early gastric and post-pyloric feeding in critically ill patients: A meta-analysis. Intensive Care Med 2006;32:639-49.

19. Hsu CW, Sun SF, Lin SL, Kang SP, Chu KA, Lin CH, et al. Duodenal versus gastric feeding in medical intensive care unit patients: A prospective, 
randomized, clinical study. Crit Care Med 2009;37:1866-72.

20. Boulton-Jones JR, Lewis J, Jobling JC, Teahon K. Experience of post-pyloric feeding in seriously ill patients in clinical practice. Clin Nutr 2004;23:35-41.

21. Kreymann KG, Berger MM, Deutz NE, Hiesmayr M, Jolliet P, Kazandjiev G, et al. ESPEN Guidelines on Enteral Nutrition: Intensive care. Clin Nutr 2006;25:210-23.

22. Heyland DK, Dhaliwal R, Drover JW, Gramlich L, Dodek P, Canadian Critical Care Clinical Practice Guidelines Committee. Canadian clinical practice guidelines for nutrition support in mechanically ventilated, critically ill adult patients. JPEN J Parenter Enteral Nutr $2003 ; 27: 355-73$
23. Martindale RG, McClave SA, Vanek VW, McCarthy M, Roberts P, Taylor B, et al. Guidelines for the provision and assessment of nutrition support therapy in the adult critically ill patient: Society of Critical Care Medicine and American Society for Parenteral and Enteral Nutrition: Executive Summary. Crit Care Med $2009 ; 37: 1757-61$

How to cite this article: Friedman G, Flávia Couto CL, Becker M. Randomized study to compare nasojejunal with nasogastric nutrition in critically ill patients without prior evidence of altered gastric emptying. Indian J Crit Care Med 2015;19:71-5.

Source of Support: Nil, Conflict of Interest: None declared.

\section{Author Help: Reference checking facility}

The manuscript system (www.journalonweb.com) allows the authors to check and verify the accuracy and style of references. The tool checks the references with PubMed as per a predefined style. Authors are encouraged to use this facility, before submitting articles to the journal.

- The style as well as bibliographic elements should be $100 \%$ accurate, to help get the references verified from the system. Even a single spelling error or addition of issue number/month of publication will lead to an error when verifying the reference.

- Example of a correct style Sheahan P, O'leary G, Lee G, Fitzgibbon J. Cystic cervical metastases: Incidence and diagnosis using fine needle aspiration biopsy. Otolaryngol Head Neck Surg 2002;127:294-8.

- $\quad$ Only the references from journals indexed in PubMed will be checked.

- $\quad$ Enter each reference in new line, without a serial number.

- $\quad$ Add up to a maximum of 15 references at a time.

- If the reference is correct for its bibliographic elements and punctuations, it will be shown as CORRECT and a link to the correct article in PubMed will be given.

- If any of the bibliographic elements are missing, incorrect or extra (such as issue number), it will be shown as INCORRECT and link to possible articles in PubMed will be given. 